\title{
As relações de poder no trabalho da Estratégia Saúde da Família
}

\author{
Power relations in the work of Family Health Strategy
}

\author{
Eliana Aparecida Villa', Antônia Vitória Soares Aranha², Liliane de Lourdes Teixeira Silva ${ }^{\mathbf{3}}$, \\ Cristina Rabelo Flôr $\mathbf{4}$
}

RESUMO Trata-se de pesquisa qualitativa que tem por objetivo analisar as relações de poder estabelecidas no trabalho da Estratégia Saúde da Família. Foram realizadas entrevistas semiestruturadas com dezenove profissionais integrantes de três equipes e utilizados registros efetuados a partir de observação participante. Os dados foram analisados segundo Bardin e categorizados em duas unidades analíticas. $\mathrm{O}$ estudo demonstrou que alguns paradigmas são difíceis de modificar, especialmente quando são vistos de forma natural pelos envolvidos. No entanto, avanços foram verificados a partir do posicionamento daqueles muitas vezes vistos como inferiores nas relações de poder desse serviço.

PALAVRAS-CHAVEAtenção PrimáriaàSaúde;EstratégiaSaúdedaFamília;Relaçõesinterprofissionais.

ABSTRACT It is a qualitative study that aims to analyze the power relations established in the work of the Family Health Strategy. Semi-structured interviews with nineteen professional members of three teams were conducted and records obtained from participant observation were used. Data were analyzed according to Bardin and organized into two analytical categories. The study showed that some paradigms are difficult to modify, especially when they are seen as natural by the involved people. However, advances have been verified from the positioning of those often seen as inferiors on power relations in this service.

KEYWORDS Primary Health Care; Family Health Strategy; Interprofessional relations.

1 Universidade Federal de Minas Gerais (UFMG) Belo Horizonte (MG), Brasil. luavilla@gmail.com

2 Universidade Federal de Minas Gerais (UFMG) Belo Horizonte (MG), Brasil. antoniavitoria@uol.com.br

3 Universidade Federal de São João Del Rei (UFSJ) - São João Del Rei (MG), Brasil. lilanets@ufsj.edu.br

4 Universidade Federal de São João Del Rei (UFSJ) - São João Del Rei (MG), Brasil. cristinaflor@ufsj.edu.br 


\section{Introdução}

O campo da saúde se constituiu a partir de uma relação de poder-saber presente no processo de trabalho. Segundo Foucault (1986), a profissionalização dos técnicos se deu por meio da articulação entre saber e poder médico, instituindo-se uma série de práticas disciplinares de regulação das relações e do espaço institucional a partir da hegemonia médica, em torno da qual foram se constituindo todas as demais profissões.

O poder só existe em ato. É sempre relacional, um modo de ação de uns sobre os outros. O poder envolve as relações entre dois ou mais atores sociais, nas quais o comportamento de um é afetado pelo comportamento do outro; o poder expressa a capacidade que um indivíduo tem de levar o outro a fazer algo que de outra maneira não faria, por imposição (FOUCAULT, 1986).

A visão foucaultiana desconstrói a percepção de que há um polo que somente domina e outro que somente sofre a dominação. $\mathrm{O}$ poder é exercido numa cadeia de submissões da qual ninguém é o alvo único, mas perpassa os diferentes indivíduos. Foucault amplia essa noção na medida em que não busca identificar o polo dominante ou o dominado, mas entender a posição, os sentidos e as relações de cada sujeito na rede de dominação.

O poder presente nas relações também propicia a produção do saber, e uma das formas de fazê-lo é pela resistência dos trabalhadores. $\mathrm{O}$ autor assinala que se o poder fosse somente repressivo, não teria a força que tem: "ele produz coisas, induz ao prazer, forma saber, produz discurso" (FOUCAULT, 1986, P. 8).

Sob outro enfoque, discutindo a teoria weberiana de poder, Cecílio (1999) afirma que o poder, quando exercido de forma legítima, tem o sentido de autoridade. A dominação legítima baseia-se na crença em ordens e no direito de mando daqueles nomeados para exercer a dominação. É o tipo de poder existente no interior das organizações formais, constituído por meio de estruturas burocráticas conformadas em verdadeiras pirâmides hierárquicas de autoridade.

Segundo Cecílio (2011), a gestão do cuidado está atrelada à cooperação de diversos atores coexistindo em diferentes espaços marcados por disputas, acordos e assimetrias de poder. Nesse sentido, Sulti et al. (2015) assinalam que os trabalhadores da saúde misturam em seu trabalho diário compromissos normativos e papéis institucionais com suas práticas personalizadas.

As relações de poder também são evidentes na Estratégia Saúde da Família (ESF). São profissionais que vivenciam relações geradoras de conflitos em virtude da diversidade de opiniões e posturas. Em alguns casos, há tentativa de dominação profissional com centralização da organização do serviço, ainda que esta não seja oficialmente instituída (LANZONI; MEIRELES, 2012).

A ESF propõe um modelo de organização voltado para maiores aproximação e valorização da comunidade, em detrimento da centralização profissional, buscando sair de um padrão de atenção médico-centrado para uma proposta multidisciplinar horizontalizada e integradora (BRASIL, 2012).

Contudo, a realidade do trabalho em equipe na ESF ainda se distancia do que é preconizado para a efetivação de uma atividade multiprofissional e compartilhada. Conforme alertam Lanzoni e Meirelles (2012), há uma inexistência de responsabilidade coletiva entre os membros da equipe, o que gera descontinuidade entre as ações específicas de cada profissional e uma pobre interação entre eles frente às atividades de trabalho.

Historicamente, o médico assume a posição de poder na equipe de saúde, de forma natural. Nesse sentido, Costa e Martins (2011) afirmam que o conhecimento específico dos médicos garante, tradicionalmente, legitimidade para exercer o controle sobre os demais membros da equipe e usuários.

Dessa maneira, torna-se relevante desvelar as relações de poder-saber presentes no trabalho da ESF, visando a uma maior integração 
entre os trabalhadores que permita a realização de uma assistência de melhor qualidade. Portanto, este estudo tem como objetivo analisar as relações de poder-saber que se estabelecem entre os integrantes de Equipes de Saúde da Família (EqSF).

\section{Metodologia}

A trajetória metodológica adotada foi uma abordagem qualitativa, que possibilita a imersão em um universo de saberes e significados dos sujeitos envolvidos na pesquisa, além de permitir compreender os movimentos sociais, culturais e a relação entre pessoas e instituições (MINAYO, 2014).

$\mathrm{O}$ projeto de pesquisa foi submetido ao Comitê de Ética em Pesquisa da UFMG, sendo aprovado sob o parecer $\mathrm{N}^{\mathrm{o}}$ ETIC 420/05 e Protocolo CAAE - 0420.0.203.00005. Os dados foram coletados nos meses de março, abril e maio de 2007.

O estudo foi realizado com membros de três EqSFs de um Centro de Saúde do município de Belo Horizonte (MG). Participaram da pesquisa dezenove profissionais de saúde, sendo três médicas $(M)$, seis auxiliares de enfermagem (AE), três enfermeiras (E), seis agentes comunitários de saúde (ACS) e a gerente da unidade (G). Todos os integrantes consultados (das três equipes) concordaram em participar. A obtenção dos discursos encerrou-se quando ocorreu a saturação dos dados, percebendo-se ter atingido uma descrição suficiente do fenômeno.

Para realização da pesquisa qualitativa, optou-se pela entrevista semiestruturada e pela observação participante, registrada em diário de campo. A pesquisadora permaneceu em imersão no serviço por três meses. Foram elaborados 27 relatórios, com observações das atividades realizadas no Centro de Saúde nos dois períodos: manhã e tarde.

Os resultados foram obtidos a partir da exploração do material por meio de codificação, numeração e classificação do conteúdo coletado nas entrevistas, norteados pela análise de conteúdo de Bardin (2011). A análise resultou na construção de duas categorias: 'As relações de poder na saúde da família' e as 'Mudanças de paradigma nas relações de poder'.

Os participantes do estudo foram identificados com a(s) letra(s) da categoria profissional a que pertencem e numerados conforme a ordem da entrevista, com vistas à manutenção do anonimato.

\section{Resultados e discussão}

\section{Categoria 1: As relações de poder na saúde da família}

Nesta categoria são relatadas as relações de poder existentes entre as diferentes classes de profissionais da EqSF, e entre esses e os usuários do serviço de saúde.

Foi possível constatar, por meio da presente investigação, que as relações de poder-saber estão vívidas entre os integrantes das ESF, porém, ocorrem de forma naturalizada. Ao serem questionados sobre a existência do poder na convivência diária, a maioria dos trabalhadores não a identificou diretamente, enfatizando o bom relacionamento entre todos. No cotidiano do serviço, ficou evidente o estreitamento das relações entre os diferentes profissionais, entretanto, prevalece uma memória cristalizada de uma hierarquia objetiva e impessoal.

Detalhes atitudinais denunciaram os comportamentos diferenciados entre os membros das equipes. Pode-se relacionar alguns deles, tomando alguns trechos das descrições contidas nos diários de campo: nas reuniões, as opiniões das médicas foram as primeiras a serem solicitadas; em três, das cinco reuniões observadas, os assuntos iniciais foram os que envolviam as médicas, para poderem sair logo após suas participações; as enfermeiras e técnicas de enfermagem, ao 
entrarem nos consultórios, mesmo fora do atendimento médico, fizeram-no com mais cerimônia que junto aos outros profissionais; as solicitações e os diálogos são mais formais quando dirigidos às médicas.

A presença do poder nas relações da equipe da ESF é declarada por uma das médicas:

Eu acho que ainda existe, sim, essa questão do poder na saúde, infelizmente. A questão do poder, principalmente do médico [...]. O médico tem um poder de decisão muito maior que o enfermeiro, o auxiliar [...] Acho isso péssimo! Às vezes, quero que o auxiliar participe mais da reunião, ou o enfermeiro se posicione, mas eles têm medo de falar porque 'o médico pode não gostar'. $\left(M_{1}\right)$.

Embora o trabalho da ESF se apresente com uma estruturação mais horizontalizada, permanece uma conduta na qual o médico é a figura central, uma autoridade, mostrando que independentemente dos lugares ocupados pelos vários trabalhadores, relações de poder são marcantes na hierarquia entre os profissionais.

Segundo Costa e Martins (2011), essa hierarquia se estende, também, à relação profissional/usuário, comprometendo a autonomia dos envolvidos no processo assistencial. Nesse sentido, por vezes, o usuário chega ao serviço em estado de dependência e de alienação, esperando respostas e soluções, principalmente do médico, como aponta o relato abaixo:

[...] Como médica, a minha experiência aqui e também em outros lugares mostra que, por mais que você tente que o paciente seja mais independente, assuma sua parte, no final, ele volta e quer que você resolva tudo, a todo custo. E querem sempre o remédio [...]. É um hábito já internalizado. $\left(\mathrm{M}_{3}\right)$.

A persistência da submissão do usuário ao saber dos profissionais só se mantém porque tanto um quanto outro alimenta essa lógica. Cadoná e Scarparo (2015) salientam que, mesmo com a utilização de práticas consideradas emancipatórias e participativas, há evidências de uma postura submissa dos usuários, que permanecem na expectativa de modelos de conduta e de prescrições.

Vale ressaltar que essa relação poder-saber presente nos serviços de saúde resulta de uma complexa e engenhosa construção social, que, ao longo do tempo, foi se cristalizando no imaginário social, como o poder do médico sobre a vida e a morte do indivíduo, e, por isso, a suposta diferença desse profissional com relação aos demais:

\section{Ah, não sei se posso chamar de 'poder'... Mas a re- lação na equipe depende, sim, muito do médico. Ele que decide. $O$ [médico] que estava aqui ficava mais na dele... Aí, a gente também não se sente à von- tade pra comentar nada. Sei lá se ele vai gostar, se vai achar que a gente está falando o que não deve, então a gente acaba é ficando quieta, né? $\left(\mathrm{AE}_{1}\right)$.}

A atitude de 'ficar quieta', assumida pela trabalhadora, pode ser a expressão de um comportamento naturalizado, que acusa uma diferença hierárquica entre ambos. A trabalhadora, em seu discurso, manifesta uma posição enunciativa marcada por uma distância interna, cunhada nas distâncias social e profissional entre as distintas categorias.

Sobre o domínio do poder-saber, Foucault (1995) destaca que em qualquer circunstância dialógica pode haver disputa pelo poder, ainda que nem tudo seja dito de maneira direta. Nesse sentido, o que não é dito pode permanecer subentendido, como mostra o fragmento do discurso de uma das enfermeiras:

Aqui tem, sim, apenas uma médica do grupo de apoio que destoa dos demais, porque se coloca como superior, não em relação aos seus colegas médicos, mas aos enfermeiros e demais profissionais. É uma postura como se os outros fossem 'os burros'! É assim que eu vejo. É uma pessoa muito difícil. E com essa pessoa não é possível troca nenhuma. A pessoa que te impõe alguma coisa [...], mantém uma distância [...]. $\left(E_{1}\right)$. 
O depoimento expressa o poder sobre as práticas articuladas ao saber científico, o que nos remete a Pires (2011), quando afirma que os enfermeiros têm dificuldade de analisar as relações de poder presentes no trabalho da equipe e no serviço de saúde, fato que compromete o caráter político do seu agir e enfraquece seu discurso e seus posicionamentos.

Outro olhar sobre o tema diz respeito ao poder legal-administrativo presente nas instituições de saúde, mesmo aquelas que têm as estruturas mais horizontalizadas (CECíLIO, 1999; 2011). A maneira hegemônica de gestão, ainda presente na ESF, contribui para manter inalterados a hierarquização e o autoritarismo nas relações entre gestores, trabalhadores e usuários, sem produzir maior eficácia e eficiência desejadas (SULTI ET AL., 2015).

A fala de uma das auxiliares de enfermagem ilustra a hierarquia existente:

Quanto ao poder, acho que a gente tem uma hierarquia de trabalho pra respeitar: a gerente, o médico, o enfermeiro, pra organizar o trabalho. Claro que eles têm poder. Não que você tenha que ser submissa, mas a enfermeira, a gerente tem poder sobre mim, funcionária. $\left(\mathrm{AE}_{4}\right)$.

No Centro de Saúde em estudo, as decisões são tomadas por um Colegiado Gestor que representa o conjunto de trabalhadores. Trata-se de uma autonomia relativa, pois o Colegiado decide a partir das determinações superiores do Distrito, que detém o poder legal-administrativo. Para Cecílio (2011), os gestores são percebidos como elementos externos à equipe, por vezes, vistos como superiores e inatingíveis, fato refletido no distanciamento desses com os trabalhadores e suas necessidades, conforme apontam os discursos: "Aqui a gente só tem deveres. Os direitos ficam esquecidos" $\left(\mathrm{E}_{1}\right)$.

Há um grande desrespeito dos gestores com o profissional, porque eu tive um problema sério com eles: fiz um atendimento correto de uma Senhora, mas que ela não concordou e mandou uma carta de todo tamanho ao órgão gestor, que respondeu à usuária se des-cul-pan-do pelo atendimento! Recebemos essa cópia, e eu fiz questão de ir até lá, falar pessoalmente, porque, antes de darem razão ao usuário, eles têm que consultar a gente, saber o que aconteceu realmente. $\left(E_{2}\right)$.

As entrevistadas manifestaram insatisfação com as cobranças frequentes dos superiores quanto às obrigações no trabalho e com a falta de apoio recebido quando se trata dos seus direitos. Conforme Sulti et al. (2015), na gestão dos serviços estão presentes os desejos, as necessidades e os interesses dos trabalhadores, incluindo os saberes, o poder e o modo de operar as relações. Para os autores, a articulação e as diferentes formas de gestão dependem dos gestores, que devem estar voltados não somente para a produção de saúde, mas para a efetivação dos princípios do Sistema Único de Saúde (SUS).

A tecnologia do poder-saber funciona de forma interligada às normas institucionais explícitas e implícitas. Todos os trabalhadores e usuários fazem parte da teia de poderes, podendo sujeitar e submeter o outro, quando no lugar de quem detém o poder:

[...] Mas na minha equipe tem isso [a enfermeira fala]: 'Eeeeeu sou suunua enfermeira e você é miiiiiiiiinha auxiliar! [...] você faz aquilo que eu mando'[...]. Eu já pensei em me desligar do PSF, mas, no momento, por questões financeiras, eu não posso de jeito nenhum. $\left(\mathrm{AE}_{2}\right)$.

O enfermeiro sente-se subjugado na relação com o médico e os gestores e, como coordenador da equipe de enfermagem, assume uma postura de 'mando' com relação ao auxiliar de enfermagem, determinando as ações que devem ser cumpridas. Para Garcia et al. (2014), na coordenação do processo de trabalho da ESF, o planejamento é um meio de exercer o poder. Pode ser um instrumento decisório, bem como uma ferramenta de dominação, cerceando a possibilidade do 
trabalhador de intervir, manifestar-se e participar das ações planejadas.

A teia de poder-saber pode ser percebida, também, na distinção feita pelo usuário:

Outro dia, já falei pra enfermeira: 'qualquer dia você precisa ir comigo, mas não vai de branquinho, não, vai é de abada [uniforme do ACS] [...] Aí você vai ver como eles vão te tratar. Aí, sim!'. $\left(A C S_{1}\right)$.

A distinção relatada reflete a diferença hierárquica de poder atribuída a cada categoria, como declarado por outra trabalhadora:

Outro dia, no acolhimento, um rapaz chegou, me xingou de tudo quanto é nome, porque estava demorando a consulta [...]. Na hora que ele entrou aqui no consultório, abriu a porta, foi todo manso com a enfermeira, como se nada tivesse acontecido. A linguagem deles com a gente é outra [...] a gente fica com as cacetadas. $\left(\mathrm{ACS}_{2}\right)$.

A linguagem é um elemento essencial na relação de poder-saber entre trabalhador/ usuário, mas pode atuar como forma de dominação. Por meio da linguagem, é possível influenciar o comportamento do outro visando a atingir os objetivos almejados. Tal função fica explícita nas relações de trabalho, já que a linguagem é muito mais desenvolvida e facilitada por aqueles que detêm o poder. É o que mostra o discurso:

Alguns parece que têm medo de falar com o médico! Chegam pra mim e pedem: fala pra ele! [...] Mas eu entendo, porque tem médico que não dá a mínima, pensa que sabe tudo [...]. Aqui na equipe isso já mudou. $\left(\mathrm{AE}_{4}\right)$.

O usuário, em circunstâncias diversas, não dispõe de todos os termos e condições para descrever seu estado e fica inibido diante de quem, para ele, detém o poder-saber. De modo geral, pouco questiona, e é comum sair do atendimento com dúvidas, buscando esclarecimentos junto aos outros profissionais:
[...] Tem também muitos pacientes que vêm tirar dúvidas com a gente. Saíram da consulta e vêm perguntar pra gente. Aí você pergunta: - Mas a médica não Ihe explicou isso? Não explicou ou ele não entendeu? Mas chega pra gente, e aí você vai detalhando as coisas. Eu acho que com o médico eles ficam um pouco receosos, principalmente os mais humildes [...]. $\left(\mathrm{AE}_{3}\right)$.

Segundo Faïta (2007), o sujeito produz discursos a partir de uma posição e de um contexto determinado, influenciado por outras falas, anteriores e posteriores ao seu enunciado, mobilizando saberes diversos para a compreensão da relação interativa daquele momento. A linguagem é uma ação e permite uma atuação direta sobre as pessoas. Ela é uma construção de sentido em uma situação singular que se expressa nas palavras.

O trabalho na ESF sugere, entre outros fatores, a compreensão da linguagem e os simbolismos que a constituem, tais como as formas de comunicação, a participação, o mal-entendido, o não dito, a interpretação, bem como as diferentes formas de expressão (FAÏTA, 2007). Tal fato é comprovado no depoimento: "Tem um rapaz da minha equipe que falava daquele médico: 'Ele é só na dele, tá nem aí. Aí eu não consigo falar quase nada. É como se diz: eu entro mudo e saio calado"” $\left(\mathrm{AE}_{2}\right)$. No silêncio do usuário, a expressão de não se sentir visto pelo profissional.

A medicina exerce um poder histórico nas relações de cuidado, concentra o poder do diagnóstico e da intervenção terapêutica, cumprindo uma autoridade técnico-científica. No entanto, apesar da existência subjetiva dessa relação de poder, moralmente, médico e paciente são indivíduos sem distinção (AGUIAR; OlIVEIRA; SCHRAIBER, 2013). Nessa direção, Cecim e Merhy (2009) colocam que, a depender das relações estabelecidas entre usuário e profissional, esse poder pode produzir a tirania do distanciamento e uma atitude de total desatenção para com os aspectos psicossociais do sujeito.

Assim, deve-se ressaltar que diferentes relações de poder-saber são estabelecidas no 
ambiente de trabalho da EqSF, devendo ser traçadas estratégias que visem a horizontalizar as relações de trabalho e cuidado, conforme previsto nas diretrizes da ESF.

\section{Categoria 2: Mudança de paradigma}

Nesta categoria analítica, serão discutidas novas formas de vivenciar o poder-saber, propondo novos paradigmas direcionadores dessas relações.

A valorização dos sujeitos, trabalhadores e usuários permite alterar radicalmente as relações de poder-saber e seu reflexo nas práticas da saúde. Historicamente, podemos acompanhar as diferentes estratégias articuladas pelos profissionais em busca de saídas, que resultaram em conquistas e no consequente desenvolvimento do trabalho:

Alguns colegas não se comprometem [...], mas eu acredito que a gente pode mudar [...] precisamos organizar melhor nossos trabalhos, se impor mais, sabe? Eu tenho muito mais potencial pra outras coisas do que ficar só ouvindo queixas, por isso vou à luta. $\left(E_{1}\right)$.

Novos modos de produção de saúde se estabelecem a partir da resistência do trabalhador, presentes nas diferentes e singulares formas de gerir seu trabalho. Nas palavras de Barros e Barros (2007, P. 61), “o trabalhador não é mera vítima que sucumbe às sistemáticas tentativas de desqualificação [...], ele (re) existe, (re)criando o próprio processo de trabalho". Abrem-se, assim, possibilidades no dizer ou no fazer, nas formas de relação, no confronto e na resistência, na gestão singular e coletiva da saúde e da vida.

É o que pode ser constatado quando as trabalhadoras, buscando driblar as dificuldades, encontram as saídas, estabelecendo novas normas, novos meios de desenvolver suas atividades:

Agora, eu vejo que tenho que contribuir e que tenho muuuuuito pra contribuir. Antes, nem abria a boca e até pensava: - quando isso vai mudar? [...] Agora, dou a maior força pras colegas, pra a gente participar de tudo $\left(\mathrm{AE}_{3}\right)$. Mas estamos num momento de transição ainda, porque com o outro médico não tinha nada disso, não. Ele era ele e pra ele só. Você falava alguma coisa, e ele ouvia e balançava a cabeça [...]. Hoje, com a outra médica, tem uma troca mesmo, e a gente discute junto. $\left(\mathrm{AE}_{1}\right)$.

Como pontua a trabalhadora, as transformações do trabalho em saúde, particularmente, na atenção primária, vêm ocorrendo paulatinamente. É a partir dos pequenos impulsos, das escolhas singulares, que as mudanças serão efetivadas.

Também entre os médicos foi assinalada a alteração de comportamento:

O médico com médico, um nem olhava a cara do outro. Era uma atitude individualista. O médico tinha uma relação só com o enfermeiro de nível superior, então, pra chegar nessa escala pro auxiliar e pro ACS, mudou muito, abriu o leque, e todo mundo saiu ganhando. $\left(\mathrm{M}_{2}\right)$.

Assim, por meio da consolidação de novas atitudes, os profissionais percebem novas formas de atuação, individual e coletiva, e estabelecem relações diferenciadas, menos hierarquizadas no modo de ser e fazer na ESF.

O usuário também pode colaborar para a criação de um novo paradigma relacional de poder-saber quando se percebe ouvido em uma escuta atentiva, aquela em que o trabalhador se dirige ao outro como sujeito da relação e não como objeto de seu discurso, permitindo ao usuário colocar mais de si no processo de cuidado.

Da experiência do usuário, de seu encontro com as propostas conceituais e atitudes a serem desenvolvidas, surgem possibilidades de mudanças a serem realizadas de uma maneira gradual:

É que o nosso trabalho não é somente técnico - não vale somente o meu saber. Tem que ter o outro lado, que envolve muito da cultura. É um 
processo lento. Hoje, eles já entram e conversam, mas a distância imposta na relação médico-paciente era muito grande. Era o médico lá em cima e o paciente cá embaixo, mas isso, aos poucos, está mudando. $\left(M_{2}\right)$.

Nessa relação de cuidado, cabe ao profissional criar condições para a construção da autonomia do sujeito, mesmo que uma autonomia relativa, porque vai depender do entendimento do usuário e da potência do profissional, naquele momento, para influenciar em um dado contexto ou situação. É no espaço relacional que ocorre o encontro entre profissional e usuário, com a constituição de vínculos e de compromissos.

É imprescindível, portanto, que o ato assistencial esteja pautado numa relação dialógica e que seja guiado por uma postura indagadora, sem o peso da hierarquia de poder-saber, para que o usuário possa se expressar a partir do vivido. E, consoante esses apontamentos, tomamos Cecílio (2011), ao enfatizar a necessidade de serem retomados os projetos de cogestão, de ultrapassá-los a partir do trabalho vivo em ato, como um espaço de produção de possibilidades e das singularidades.

\section{Conclusão}

O presente estudo retrata as diferentes relações de poder-saber entre as categorias profissionais e entre essas e os usuários da ESF, além de identificar caminhos em direção à construção de novas formas relacionais entre os envolvidos no processo de cuidado. O poder mobilizado e construído no trabalho da ESF sugere, portanto, que a gestão do poder tem a potência de modificar os sujeitos e as situações e de reverter os padrões dominantes de subjetividade no trabalho.

Nos serviços de saúde, de modo geral, foi possível constatar certa banalização das relações de poder presentes no cotidiano, tanto dos trabalhadores quanto dos usuários, manifestada na acomodação burocrática ou na omissão daqueles que a vivenciam, como também dos gestores.

A organização da ESF é elaborada e discutida, em cada um dos níveis hierárquicos, a partir da noção que os gestores têm do trabalho, sem que um consiga vislumbrar as dificuldades e a racionalidade que rege a prática dos demais. Diante da ausência de respostas ou de respostas insuficientes da gestão, alguns trabalhadores buscam contornar a situação, fazendo um uso de si ampliado, desdobrando-se e, por vezes, esgotando suas potencialidades físicas e psíquicas.

É importante ressaltar a relação de poder entre profissional e usuário, manifestada pela linguagem, que permite ao primeiro o domínio frente ao segundo. Contudo, deve-se considerar que todo sujeito é detentor de um saber próprio que o legitima. Portanto, o usuário deve ser protagonista na relação de cuidados e a linguagem não pode subjugá-lo.

Alguns paradigmas das relações de poder-saber existentes nas estruturas de serviços de saúde dificilmente são modificados, especialmente quando são vistos de forma naturalizada. No entanto, o presente estudo mostra avanços no sentido de rompimento com alguns desses padrões, por meio de atitudes singulares que refletem maior confiança e mais firmeza de posicionamento de alguns trabalhadores.

A relação de poder-saber existente entre os integrantes da ESF mostra que um implica e é implicado pelo outro, e não deve ser concebida de forma independente das vivências humanas e de um processo constante de reelaboração e de transformação do estabelecido. A aquisição de saber não pode se fazer de cima para baixo, mas pelo próprio sujeito, mediado pela interação profissional. 


\section{Referências}

AGUIAR J. M.; OLIVEIRA A. F. P. L.; SCHRAIBER L. B. Violência institucional, autoridade médica e poder nas maternidades sob a ótica dos profissionais de saúde. Cad. Saúde Pública, Rio de Janeiro, v. 29, n. 11, p. 2287-96, nov. 2013.

BARDIN, L. Análise de conteúdo. Lisboa: 70, 2011

BARROS, R.; BARROS, M. E. B. Da dor ao prazer no trabalho. In: SANTOS-FILHO, S. B.; BARROS, M. E. B. (Org.). Trabalhador da saúde: Muito prazer! Protagonismo dos trabalhadores na gestão do trabalho em saúde. Ijuí/RS: Ed. Unijuí, 2007, p. 61-71.

BRASIL. Ministério da Saúde. Secretaria de Atenção à Saúde. Departamento de Atenção Básica. Política Nacional de Atenção Básica. Brasília, DF: Ministério da Saúde, 2012.

CADONÁ, E.; SCARPARO, H. Construcionismo social na atenção básica: uma revisão integrativa. Ciência e Saúde Coletiva, Rio de Janeiro, v. 20, n. 9, p. 2721-30, 2015.

CECÍLIO L. C. O. Autonomia versus controle dos trabalhadores: a gestão do poder no hospital. Ciência e Saúde Coletiva, Rio de Janeiro, v. 4 n. 2, p. 315-29, nov. 1999.

Apontamentos teórico-conceituais sobre processos avaliativos considerando as múltiplas dimensões da gestão do cuidado em saúde. Interface (Botucatu), Botucatu, v. 15, n. 37, p. 589-99, abr./jun. 2011.

COSTA, D. T.; MARTINS, M. C. F. Estresse em profissionais de enfermagem: impacto do conflito no grupo e do poder do médico. Rev. esc. enferm. USP, São Paulo, v. 45 , n. 5, p. 1191-1198, out. 2011.

FAÏTA, D. A linguagem como atividade. In: SCHWARTZ, Y.; DURRIVE, L. (Org.). Trabalho e
Ergologia: conversas sobre a atividade humana. Niterói: EdUFF, 2007.

FOUCAULT, M. Microfísica do poder. 6. ed., Rio de Janeiro: Graal, 1986.

O sujeito e o poder. In: RABINOW, P.; DREYFUS H. Michel Foucault: uma trajetória filosófica para além do estruturalismo e da hermenêutica. Rio de Janeiro: Forense Universitária, 1995.

GARCIA, A. C. P. et al. Análise da organização da Atenção Básica no Espírito Santo: (des)velando cenários. Saúde debate, Rio de Janeiro, v. 38, n. especial, p. 221-236, out. 2014.

LANZONI, G. M. M.; MEIRELLES, B. H. S. A rede de relações e interações da equipe de saúde na atenção básica e implicações para a enfermagem. Acta Paul Enferm., São Paulo, v. 25, n. 3, p. 464-70, 2012.

MINAYO, M. C. S. O desafio do conhecimento: pesquisa qualitativa em saúde. 14. ed. São Paulo: Hucitec, 2014.

PIRES, M. R. G. M. Limites e possibilidades do trabalho do enfermeiro na estratégia saúde da família: em busca da autonomia. Rev Esc Enferm USP, São Paulo, v. 45, n. spe. 2, p. 1710-5, dez. 2011.

SULTI, A. D. C. et al. O discurso dos gestores da Estratégia Saúde da Família sobre a tomada de decisão na gestão em saúde: desafio para o SUS. Saúde debate, Rio de Janeiro, v. 39, n. 104, p. 172-182, mar. 2015.

Recebido para publicação em maio de 2015

Versão final em setembro de 2015

Conflito de interesses: inexistente

Suporte financeiro: não houve 